\title{
THE SUMMER MEETING IN LOS ANGELES
}

The thirty-eighth summer meeting and sixteenth colloquium of the Society were held at the University of California at Los Angeles from Tuesday to Friday, August 30-September 2, 1932. The meeting was preceded by that of the Mathematical Association of America. About two hundred persons attended the meeting, among whom were the following eighty-four members of the Society:

Beatrice Aitchison, O. W. Albert, L. D. Ames, C. L. Bacon, H. M. Bacon, C. R. Ballantine, J. P. Ballantine, M. A. Basoco, Harry Bateman, M. M. Beenken, Clifford Bell, E. T. Bell, B. A. Bernstein, F. J. Brand, W. A. Bratton, A. L. Buckman, J. H. Bushey, W. B. Carver, Myrtie Collier, L. P. Copeland, N. A. Court, P. H. Daus, C. H. Dix, G. G. Entz, H. J. Ettlinger, Raymond Garver, H. E. Glazier, F. L. Griffin, L. W. Griffiths, W. L. Hart, E. R. Hedrick, E. J. Hills, J. C. Hughes, G. H. Hunt, J. W. Hurst, C. A. Hutchinson, M. H. Ingraham, Dunham Jackson, C. G. Jaeger, Glenn James, C. M. Jensen, D. H. Lehmer, D. N. Lehmer, H. B. Leonard, Jack Levine, M. I. Logsdon, C. F. Luther, W. H. McEwen, James McGiffert, W. A. Manning, R. G. Mason, W. E. Mason, A. D. Michal, E. L. Mickelson, W. E. Milne, C. V. Newsom, F. W. Owens, H. B. Owens, T. S. Peterson, E. J. Purcell, Tibor Rad6, J. F. Ritt, H. P. Robertson, A. E. Ross, I. J. Schoenberg, A. A. Shaw, G. E. F. Sherwood, L. L. Smail, C. E. Smith, Gertrude Smith, D. V. Steed, F. C. Touton, S. E. Urner, H. C. Van Buskirk, H. S. Vandiver, L. E. Ward, Morgan Ward, L. E. Wear, M. J. Weiss, M. G. Whiting, G. T. Whyburn, W. M. Whyburn, C. L. E. Wolfe, E. R. Worthington.

The colloquium lectures, on Differential equations from the algebraic standpoint, were delivered on Tuesday afternoon and Wednesday, Thursday, and Friday mornings. These lectures have already appeared in book form, as volume 14 of the Colloquium Publications of this Society.

By invitation of the Committee on Program, Professors D. N. Lehmer and Tibor Radó gave, on Wednesday and Thursday mornings respectively, addresses entitled The continued fraction representing cubic and higher irrationalities and Recent work in the problem of Plateau.

Tuesday noon those attending the meetings were the guests of Provost E. C. Moore of the University of California at Los Angeles at a delightful luncheon in Kerckhoff Hall. On Tuesday afternoon the ladies of the Department of Mathematics served tea in Kerckhoff Hall. 
On Wednesday evening a joint dinner of the Society and the Mathematical Association of America was held at the Beverly Hills Hotel. Professor E. T. Bell acted as toastmaster and called upon Professor E. R. Hedrick who welcomed the guests to California. He was followed by Professor Jewell Hughes, who spoke with pleasant humor. Professor M. H. Ingraham talked about the financial situation and the membership statistics of the Society. Professor W. L. Hart gave the concluding talk of the evening.

Thursday afternoon and evening were devoted to an excursion to the California Institute of Technology, and to the Mount Wilson Observatory. Lunch was served in the Athenaeum at the Institute, and immediately afterward members were shown through its physical laboratories, being given an exhibit of artificial lightning at the High-Tension Laboratory. After dinner at the hotel on the top of Mount Wilson members were shown the hundred-inch telescope of the Mount Wilson Observatory and had an opportunity to look through the sixty-inch instrument.

After lunch on Wednesday a group photograph of those in attendance was taken.

Most of the visitors were housed in Mira Hershey Hall, and meals were served in its dining room. This building also served as social center for the meeting. The arrangements made by Professor Hedrick and the various local committees for the meetings and for the pleasure of the members while in attendance were splendidly planned and executed. All present heartily concurred with Professor Jackson when he called for a rising vote of thanks to all those who had helped in making the meetings a success.

The Council met on the evening of August 30 and various actions taken at this time were reported to the Society.

The following thirteen persons were elected to membership in the Society:

Mr. James Andrew Clarkson, Brown University;

Mr. Paul Eberhart, Brown University;

Dr. Carl H. Fischer, University of Minnesota;

Professor Lofton Leroy Garner, University of North Carolina;

Dr. Ralph Duncan James, California Institute of Technology;

Mr. Holbrook Mann MacNeille, Swarthmore College;

Professor Kenneth Sinclair Purdie, Virginia Military Institute;

Dr. Selby Lemley Robinson, Princeton University; 
Mr. Myron Frederick Rosskopf, Brown University;

Mr. Naphtaly Herman Schmellner, West Virginia University;

Dr. Walter George Warnock, Fort Hays Kansas State College;

Miss Frances H. Wiancko, University of Chicago;

As nominee of Yale University on Sustaining Membership:

Miss Miriam F. Becker, Hunter College.

In accordance with reciprocity agreements the following have joined the Society:

Professor Gino Fano, University of Turin;

Professor Harald Geppert, University of Giessen.

The following twenty persons have been elected by mail vote of the Council since its meeting in April:

Mr. Alfred L. Buckman, University of California;

Mr. Franklin Alfred Butter, Jr., Stanford University;

Mr. Livingston Hunter Chambers, West Virginia University;

Miss Eva Lou Culbreth, Columbia University;

Mr. Jack Gordon Deutsch, New York, New York;

Mr. Paul Samuel Donchian, Hartford, Connecticut;

Miss Margaret Gurney, Brown University;

Mr. Eugene Harold Hanson, Ohio State University;

Dr. Miles C. Hartley, University of Illinois;

Professor May Naramore Harwood, Syracuse University;

Mr. Max Alfred Heaslet, Stanford University;

Professor Vinton Asbury Hoyle, University of North Carolina;

Mr. Isidore N. Kagno, Bronx, New York;

Professor Chosaburo Kato, Denison University;

Dr. Ruth Glidden Mason, Berkeley, California;

Mr. Walter Prenowitz, Brooklyn College;

Dr. Helen Gertrude Russell, Wellesley College;

Mr. Herbert Benjamin Weaver, Chester, Pennsylvania;

Mr. Merritt S. Webster, University of Pennsylvania.

The following persons were reported as appointed to represent the Society: at the Centennial Celebration of the founding of the University of Richmond, Richmond, Va., May 8-10, 1932, Professor J. J. Luck; at the Centennial Celebration of the founding of Gettysburg College, Gettysburg, Pa., May 25-30, 1932, Professor F. W. Owens; on the Editorial Board of the American Year Book for a period of three years beginning with 1932, Professor Tomlinson Fort; at the inauguration of William A. 
Boylan as President of Brooklyn College, Brooklyn, N. Y., June 21, 1932, Dean G. W. Mullins.

The dates of the summer meeting in Chicago in 1933 were tentatively set as June 19-24.

The titles and cross references to abstracts of the papers read at the sessions follow below. The papers whose abstract numbers are followed by $t$ were read by title, the rest in person. The papers were read as follows: papers numbered 1 to 5 before a general session on Tuesday afternoon at which Vice-President W. A. Manning presided; papers numbered 6-32 were read before a section in Analysis on Wednesday afternoon with Professor W. E. Milne presiding; papers numbered 33-53 were read before a section in Algebra and Number Theory on Wednesday afternoon at which Professor D. N. Lehmer presided; and papers numbered 54-78 before a general session on Friday morning at which Professor M. I. Logsdon and Professor Dunham Jackson presided. Dr. Schoenberg presented paper No. 8, Dr. Martin presented paper No. 11, Professor Whyburn presented paper No. 13, Professor Ingraham presented paper No. 37, and $\mathrm{Mr}$. Botsford presented paper No. 59. Dr. Martin was introduced by Professor Michal, Mr. Deutsch by Professor G. A. Pfeiffer, Professor Cauer by Professor J. D. Tamarkin, Professor J. H. Binney by Professor G. C. Evans, Mr. Hull by Professor L. E. Dickson, Mr. Clifford and Mr. Botsford by Professor Michal, and Dr. Sperner by Professor Wilhelm Blaschke.

1. Diophantine equations from algebraic invariants and covariants, by Professor E. T. Bell. (Abstract No. 38-7-186.)

2. The degree and class of multiply transitive groups, III, by Professor W. A. Manning. (Abstract No. 38-9-200.)

3. Orthogonal trigonometric sums, by Professor Dunham Jackson. (Abstract No. 38-7-191.)

4. Note on a homogeneity property, by Professor G. T. Whyburn. (Abstract No. 38-9-217.)

5. On Nicod's reduction in the number of primitives of logic, by Professor B. A. Bernstein. (Abstract No. 38-11-238.)

6. A proof of E. H. Moore's equivalence, by Professor J. P. Ballantine. (Abstract No. 38-7-174.)

7. On the approximate solution of linear differential equations with boundary conditions, by Professor W. H. McEwen. (Abstract No. 38-7-180.) 
8. On linear functional operations and the moment problem for a finite interval in one or several dimensions, by Professor T. H. Hildebrandt and Dr. I. J. Schoenberg. (Abstract No. 38-9-198.)

9. A classification of the critical sets for functions, by Professor W. M. Whyburn. (Abstract No. 38-7-185.)

10. Invariant functionals of functional forms, by Professor A. D. Michal and Dr. R. S. Martin. (Abstract No. 38-9-219-t.)

11. A set of expansions in vector space, by Professor A. D. Michal and Dr. R. S. Martin. (Abstract No. 38-11-235.)

12. An extension of a certain theorem of Kronecker, by $\mathrm{Mr}$. H. M. Bacon. (Abstract No. 38-9-201.)

13. An application of the Dedekind cut notion to integration, by Professors E. R. Hedrick and W. M. Whyburn. (Abstract No. 38-7-181.)

14. On finite-rowed systems of linear inequalities in infinitely many variables, II, by Dr. I. J. Schoenberg. (Abstract No. 38-9216.)

15. Particular solutions of $y^{\prime \prime}+c_{1} x^{p} y^{\prime}+c_{2} x^{p-1} y=0$, which consist of the product of a polynomial by an exponential, by Professor James McGiffert. (Abstract No. 38-9-224.)

16. On analytic complexes, by Professor Solomon Lefschetz and Dr. J. H. C. Whitehead. (Abstract No. 38-7-189-t.)

17. Note on a theorem due to Bromwich, by Dr. H. L. Garabedian. (Abstract No. 38-5-158-t.)

18. Functions satisfying a generalized Lipschitz condition, by Mr. J. G. Deutsch. (Abstract No. 38-7-162-t.)

19. Systems of linear difference equations and expansions in series of exponential functions, by Professor R. D. Carmichael. (Abstract No. 38-7-171-t.)

20. Systems of three linear partial differential equations of the third order, by Mr. G. P. Wadsworth. (Abstract No. 38-7184-t.)

21. Differential fields and ideals of differential forms, by Mr. H. W. Raudenbush, Jr. (Abstract No. 38-7-187-t.)

22. Applications of an abstract existence theorem to both differential and difference equations, by Dr. O. K. Bower. (Abstract No. 38-7-159-t.)

23. A system of simultaneous bilinear functional equations, by Dr. O. K. Bower and Mr. J. D. Grant. (Abstract No. 38-7$160-t$.) 
24. Summation of functions of a complex variable, by Professor R. D. Carmichael. (Abstract No. 38-5-156-t.)

25. On the summability of double Fourier series, by Professor H. L. Miller. (Abstract No. 38-9-195-t.)

26. On the summability of triple Fourier series, by Miss Alta Odoms. (Abstract No. 38-9-209-t.)

27. On extremal surfaces, by Dr. Max Coral. (Abstract No. 38-9-210-t.)

28. On continued fractions in which the coeffcients have limiting values, by Professor H. S. Wall. (Abstract No. 38-9-218-t.)

29. Remarks on continued fractions, by Professor Raymond Garver. (Abstract No. 38-9-215-t.)

30. The Poisson integral for functions with positive real part, by Dr. W. Cauer. (Abstract No. 38-9-222-t.)

31. An elliptic system of integral equations on summable functions, by Professor J. H. Binney. (Abstract No. 38-11-237.)

32. Note on the gradient of the Green's function, by Professor G. C. Evans. (Abstract No. 38-11-236.)

33. A number theoretic machine, by Dr. D. H. Lehmer. (Abstract No. 38-9-202.)

34. On representation of integers by ternary forms, by Dr. A. E. Ross. (Abstract No. 38-9-208.)

35. On Fermat's last theorem, by Professor Glenn James. (Abstract No. 38-9-199.)

36. The arithmetical theory of linear recurring series, by Professor Morgan Ward. (Abstract No. 38-9-204.)

37. Certain aspects of the theory of equations for a pair of matrices, by Professor G. S. Bruton. (Abstract No. 38-9-196.)

38. A study of certain related pairs of square matrices, by Professor M. H. Ingraham. (Abstract No. 38-9-197.)

39. Concerning primitive groups of class $u$, by Dr. C. F. Luther. (Abstract No. 38-9-193.)

40. Non-cyclic normal division algebras of degree and exponent four, by Professor A. A. Albert. (Abstract No. 38-7-164-t.)

41. A note on normal division algebras of order sixteen, by Professor A. A. Albert. (Abstract No. 38-7-190-t.)

42. A type of abstract arithmetic allied to a Boolean algebra, by Professor Morgan Ward. (Abstract No. 38-9-206-t.)

43. The cancellation law in the theory of congruences to a double 
modulus, by Professor Morgan Ward. (Abstract No. 38-9205-t.)

44. An inversive algorithm, by Dr. D. H. Lehmer. (Abstract No. 38-9-203-t.)

45. The numbers of solutions of congruences involving only kth powers, by Mr. Ralph Hull. (Abstract No. 38-7-177-t.)

46. On general Kronecker-(integer)-synthesis of disciplines, by Dr. A. L. Foster. (Abstract No. 38-7-176-t.)

47. Note on polynomials in a Galois field, by Dr. Leonard Carlitz. (Abstract No. 38-7-168-t.)

48. On the representation of a polynomial in a Galois field as the sum of an even number of squares, by Dr. Leonard Carlitz. (Abstract No. 38-7-169-t.)

49. On the representation of a polynomial as the sum of an odd number of squares, by Dr. Leonard Carlitz. (Abstract No. 38-7$170-t$.)

50. On criteria for universality of ternary quadratic forms, by Dr. A. E. Ross. (Abstract No. 38-9-192-t.)

51. Groups $\{S, T\}$ whose commutator subgroups are abelian, by Professor H. R. Brahana. (Abstract No. 38-7-166-t.)

52. Prime-power abelian groups generated by a set of conjugates under a special automorphism, by Professor H. R. Brahana. (Abstract No. 38-7-167-t.)

53. On real quadratic fields, by Dr. Charles Wexler. (Abstract No. 38-9-225-t.)

54. On some properties of polygons related to the cuspidal cubic and a line, by Professor Clifford Bell. (Abstract No. 38-5-153.)

55. Geometry of a normed abelian group manifold, by Mr. A. H. Clifford. (Abstract No. 38-9-221.)

56. Involutorial space Cremona transformations determined by non-linear null reciprocities, by Dr. E. J. Purcell. (Abstract No. 38-9-207.)

57. The Apollonian spheres of a tetrahedron, by Professor N. A. Court. (Abstract No. 38-7-183.)

58. Simultaneous differential invariants of an affine connection and a general linear connection, by Professor A. D. Michal and Mr. J. L. Botsford. (Abstract No. 38-9-220-t.)

59. Normal representations and linear connections, by Professor A. D. Michal and Mr. J. L. Botsford. (Abstract No. 38-11234.) 
60. The place of Ananiah Shiragooni in the history of mathematics, by Professor A. A. Shaw. (Abstract No. 38-9-212.)

61. The Edgeworth taxation phenomenon, by Professor Raymond Garver. (Abstract No. 38-9-214.)

62. Misuse of postulations in theory of viscosity, by Mr. B. F. Groat. (Abstract No. 38-5-155.)

63. On topological transformations of a plane without invariant points, by Dr. E. Sperner. (Abstract No. 38-11-232.)

64. Possibilities for a universe with non-negative pressure, by Professor H. P. Robertson. (Abstract No. 38-11-233.)

65. Alternant surfaces, by Professor Clifford Bell. (Abstract No. 38-5-152-t.)

66. On 2-congruent graphs, by Dr. Hassler Whitney. (Abstract No. 38-5-157-t.)

67. On reduction of space Cremona involutions, by Miss Esther McCormick. (Abstract No. 38-7-165-t.)

68. Types of involutorial space transformations associated with certain rational curves, by $\mathrm{Mr}$. Amos Black. (Abstract No. 38-7-175-t.)

69. On certain associated metric spaces, by Mr. C. A. Lovell. (Abstract No. 38-7-163-t.)

70. Continuous transformations of finite spaces, by Dr. Rothwell Stephens. (Abstract No. 38-9-194-t.)

71. Note on triple systems, by Professor R. D. Carmichael. (Abstract No. 38-7-179-t.)

72. New sets of independent postulates for the algebra of logic, with special reference to Whitehead and Russell's Principia Mathematica, by Professor E. V. Huntington. (Abstract No. 38-7182-t.)

73. A set of postulates for the foundation of logic, Second paper, by Professor Alonzo Church. (Abstract No. 38-7-161-t.)

74. Remarks on propositions *1.1 and *3.35 of Principia Mathematica, by Professor B. A. Bernstein. (Abstract No. 389-211-t.)

75. Some properties of equality in combinatory logic, by Dr. H. B. Curry. (Abstract No. 38-5-154-t.)

76. Permanent configurations in the problem of four bodies, by Professors W. D. MacMillan and Walter Bartky. (Abstract No. 38-7-178-t.) 
77. Concerning the limits of a measure of skewness, by Professor Raymond Garver. (Abstract No. 38-9-213-t.)

78. Concerning the mapping of locally connected continua on to simple arcs, Preliminary communication, by Miss Beatrice Aitchison. (Abstract No. 38-11-231.)

M. H. Ingraham, Associate Secretary

\section{INTERNATIONAL CONGRESS OF MATHEMATICIANS,} ZURICH, 1932

BY R. G. D. RICHARDSON

Mathematicians from 37 countries to the number of approximately 650 together with 250 members of their families assembled in Zurich, Switzerland, for the Congress held September 4-12. As would be expected, the largest delegation of participants was from Switzerland (140), followed in order by Germany (111), France (68), United States and Canada (68), Italy (63), and Great Britain (38). The total attendance from this country and Canada, including members of the families of the active participants, was 104. Harvard and Brown had the largest delegations, there being four mathematicians from each. Among those who attended were the following 68 mathematicians :

C. R. Adams, R. B. Adams, J. W. Alexander, R. C. Archibald, I. A. Barnett, Garrett Birkhoff, H. F. Blichfeldt, D. G. Bourgin, R. W. Brink, W. D. Cairns, L. D. Cummings, L. L. Dines, H. L. Dorwart, H. T. Engstrom, F. J. Feinler, A. L. Foster, O. E. Glenn, M. C. Graustein, W. C. Graustein, Margaret Gurney, Einar Hille, T. R. Hollcroft, A. E. Holman, Charles Hopkins, W. A. Hurwitz, B. O. Koopman, A. M. Lehr, Florence Lewis, R. G. Lubben, E. M. Luse, Wilhelm Maier, T. E. Mason, G. M. Merriman, U. G. Mitchell, C. N. Moore, T. W. Moore, D. S. Morse, Marston Morse, Oystein Ore, R. A. C. Paley, G. Y. Rainich, R. G. D. Richardson, W. H. Roever, Stanislaw Saks, Arthur Sard, L. L. Silverman, W. G. Simon, L. G. Simons, D. E. Smith, P. A. Smith, Virgil Snyder, M. E. Stark, M. H. Stone, E. B. Stouffer, J. L. Synge, J. D. Tamarkin, Stepan Timoshenko, A. W. Tucker, J. S. Turner, H. W. Tyler, Oswald Veblen, H. M. Walker, J. L. Walsh, D. W. Weeks, J. H. C. Whitehead, D. V. Widder, Norbert Wiener, F. B. Williams.

The morning hours were occupied by 21 one-hour addresses given by invitation. This list included two presented by Americans and these were among the very best in material and form. 